事

\title{
INVASION OF PERSONAL SPACE UNDER THE CONDITION OF SHORT-TERM CROWDING: A CASE STUDY ON AN AUTOMATIC TELLER MACHINE
}

\author{
Naz Kaya And Feyzan ERKíp \\ Department of Interior Architecture and Environmental Design, Bilkent University, Ankara, Turkey
}

\begin{abstract}
This study is an investigation of the effects of short-term crowding on the invasion of personal space. The analysis was carried out by means of research designed for automatic teller machine (ATM) users in Ankara. The activity, withdrawing money from an ATM, requires certain levels of privacy which may vary with the personal characteristics of the individuals. Among these, sex of the user is considered an important factor. Also, situational variables such as density conditions have an effect on interpersonal distance. The survey was carried out through participant observation and short interviews with the users under two - low and high — density conditions. It was found that personal space was invaded more under high density conditions and when the space was perceived as narrower. However, this did not cause a significant difference in the privacy requirements of the users as they mostly preferred a private space under both density conditions. Sex did not appear to be a dominating factor in this choice although people of opposite sexes tended to keep longer distances between them. The only difference was the females'approach to males which was more distant than males'approach to females. Utilizing the findings of this research, appropriate design solutions for an indoor ATM hall were proposed. (C) 1999 Academic Press
\end{abstract}

\section{Introduction}

The studies on human-environment relationships include a broad spectrum of variables and situations. A number of studies focus on intrusion into personal space (Patterson et al., 1971; Krail \& Leventhal, 1976; Wollman et al., 1994), whereas others deal with people in intimate relationships or examine the relationship between unacquainted individuals (Aiello, 1987; Veitch \& Arkkelin, 1995). Some focus on people with different personality characteristics (Sommer, 1969), whereas others deal with people from different cultural backgrounds (Evans \& Howard, 1973; Hayduk, 1983; Altman \& Chemers, 1989; Remland et al., 1995). Most research related to the study of interpersonal distance preferences has been conducted in public spaces such as libraries, airports, schools, offices, and restaurants (Hall, 1966; Sommer, 1969; Hortaçsu et al., 1990; Larner, 1993).

Crowding refers to the psychological state of discomfort and stress associated with the spatial aspects of the environment (Sears et al., 1988). If the expectations on the use of space are violated by the presence of others, the feeling of being crowded is induced.
Therefore, emotional distress may arise and some behavioral adjustments aimed at preserving one's personal space may occur.

Environmental psychologists who regard personal space as a spacing mechanism tend to refer to personal space as interpersonal distance (Hall, 1966). Interpersonal distance informs both participants and observers about the nature of the participant's relationship to others (Gifford, 1987). However, there are some factors influencing the determination of the distance and orientation preferred by the individuals. Personal characteristics of the individuals have an important role on interpersonal distancing. Sex of the individual and sex of the invader have an effect on social interaction (Altman \& Chemers, 1989). Some studies reported that males use larger distances than females (Kuethe, 1962; Evans \& Howard, 1973; Fisher \& Byrne, 1975; Gifford, 1982). Females interacting with females have been found to exhibit smaller personal space zones than males interacting with males (Sommer, 1959; Baxter, 1970). However, Becker (1973) failed to find support for the sex effect. One possible reason is that sex differences occur due to the differences in the socialization of males and females, 
which should vary with the cultural context. Similarly, Rüstemli (1986) explains inconsistent findings about sex effects on personal space within the cultural context in which these studies are conducted.

In addition, situational variables have an influence on interpersonal distance. High density usually affects social interaction between individuals. An increase in the number of people or decrease in the amount of available space (indicating social and spatial density, respectively) leads to high density situations in which individuals may feel uncomfortable. When social density increases and interpersonal distance between individuals decreases, the feeling of being crowded increases (Gifford, 1987). The same amount of resources must be distributed to a higher number of people, more physical interference is encountered, hence the sense of control and privacy are reduced. Particularly, when social density is undesirable, social outcomes are generally negative and more aggression and less cooperation occurs. According to Horn (1994), crowding leads to a number of social behaviors. People tend to like people less when they feel crowded than when they do not. Another study conducted by Jain (1987) with two levels of density (low and high) and two levels of resources (sufficient and scarce) indicated that the feeling of crowding is related to high density and scarcity of resources. The results suggest that there is an increase in competition under conditions of social density and scarce resources. Furthermore, Desor (1972) demonstrated that the type of activity significantly affects the degree to which occupants perceive crowding. As well as this, lack of control over the environment can cause some people to feel psychologically distressed. Loo (1977) hypothesized that negative effects of crowding are more likely to emerge when people's activities involve social interaction or when territorial intrusions occur.

Individuals subjected to high density often respond by withdrawing from social interaction and avoiding social contact. Social withdrawal is manifested in several ways such as moving away, choosing less personal topics to talk about, making remarks about leaving (Sundstrom, 1975), turning away, avoiding eye contact (Hall, 1966), or increasing interpersonal distance (Baum \& Greenberg, 1975; Baum \& Paulus, 1987). These behaviors that are utilized to protect personal space under crowded conditions give clues for the empirical survey of this study.

As a starting point, public spaces where people can wait in a queue were observed in order to search for the effects of short-term crowding on interpersonal distance and automatic teller machines (ATMs) were found appropriate for the purpose of this study. As the case study was conducted at a single ATM (a fixed space) social density was assumed to be the reason for the feeling of crowding. The activity allows observation of short-term crowding where two levels of density, low and high, can be studied. Since no research related to the study of the interrelationship of environment and behavior at ATM spaces has been reported, it was also considered an original site for analysis. In this study, the effects of short-term crowding were investigated in relation to personal space invasion at an indoor ATM hall. Sex differences and situational variables such as density conditions were accepted as the most important factors whereas physical, cultural, demographical, and psychological factors were considered to the extent required by the main factors.

\section{Method}

\section{Subjects}

Subjects were chosen through quota sampling (Marriott, 1990; Vogt, 1993). That is, the number of subjects both in low and high density conditions were kept equal at the end of the research. The size of the sample group was 200 with 100 subjects under each density condition. The subjects waiting alone in the queue were selected in order to eliminate the possible interactions among them. To examine the role of sex differences on interpersonal distance preference, sex of the subject and sex of the invader were also considered in sampling and so there were four possible combinations: male-male, male-female, female-female and female-male. All four combinations were observed under conditions of both low and high density.

\section{Setting}

In Ankara many banks have ATMs. Yapi Kredi Bank was chosen because it had the maximum number of indoor ATM branches, so the possibility of choosing an appropriate setting was higher. The second reason was that this bank had the first indoor ATM design in Ankara. To decide on the specific location, a number of criteria were considered: having a single machine, being located in indoor space, having enough space in order to be able to make observations, and being frequently used. According to these criteria, Sihhiye branch of Yapi Kredi Bank in Necatibey Avenue was chosen (see Fig. 1). It is an indoor space having a single ATM. There is no other branch nearby, so it was expected to be visited frequently. Finally, the ATM hall has an adequate area for observation (approximately $16 \mathrm{~m}^{2}$ ). 


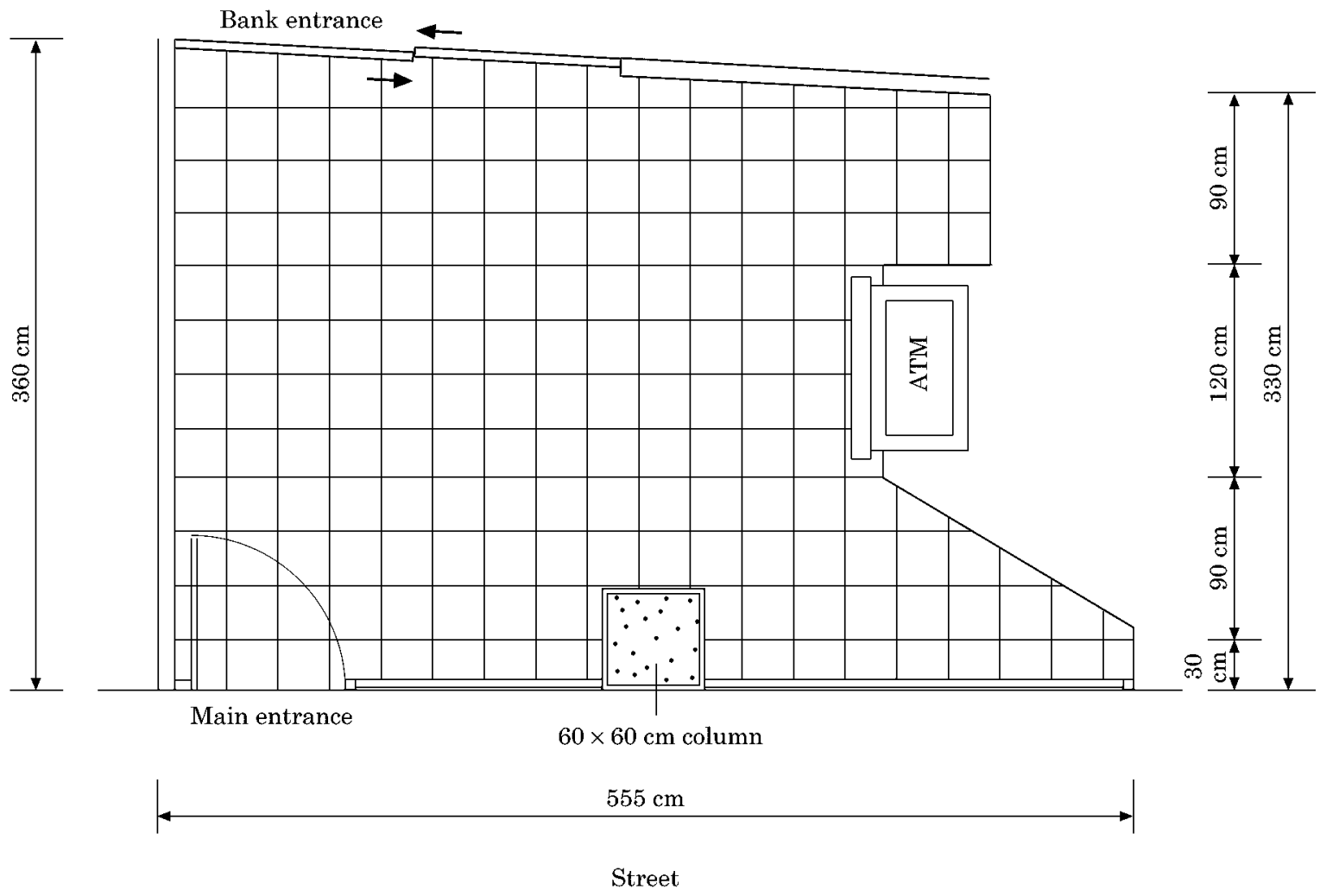

Figure 1. Floor plan of the ATM hall.

\section{Procedure}

The survey research consists of two parts: participant observation (Bechtel \& Zeisel, 1990) and questionnaire. First, the behavior of the individual who was using the machine (the first person in the queue) was observed. The types of behavior of the first individual, for example looking around, looking at the person standing behind, hiding the ATM screen from others, and making verbal response to the person standing behind were indicated on the observation form. The sex of the people waiting in the queue was also recorded. Along with these, the preferred interpersonal distances between individuals in the queue were recorded. These distances were divided into three intervals: $15-45,46-75$ and $76-120 \mathrm{~cm}$, which were based on Hall's (1966) Proxemic Theory and represent intimate distance-far phase, personal distance-near phase, and personal distance-far phase, respectively. Observations during the pilot study indicated that the distances utilized by the users were in accordance with the above phases. They were measured approximately with the help of the floor covering which consisted of $30 \times 30 \mathrm{~cm}$ ceramic tiles.
The second part of this research was conducted through a questionnaire which was given to the first person in the queue, when he/she completed his/her operation and left the ATM hall. It was made up of questions about the opinion of subjects on the spatial aspects of the space, security concerns, opinion about the presence of others in the ATM hall, degree of importance the individual gives to the sex of the person standing behind, and demographic characteristics of the respondents such as age, education, occupation, and district in which he/she lives.

Density conditions were determined according to the number of people waiting in the queue at the indoor ATM hall. From two to four individuals was considered low density, whereas five and over was considered high density. These levels were decided according to the space limitation of the indoor ATM hall. As the location of this ATM site is a central workplace, it is expected to be more crowded during weekdays and lunch hours. Therefore, to satisfy high density conditions, the observations were conducted on weekdays, from 12:00 pm to 2:00 pm. Observations were carried out at weekends, from 12:00 pm to 2:00 pm for low density. Time sampling was also 
supported by the pilot study including various observations at the site.

\section{Hypotheses}

Hypotheses of this study are as follows.

(1) People maintain smaller distances in high density situations compared to low density and they perceive the space as being narrower.

(2) In high density conditions, subjects get more annoyed with the presence of others standing behind and make some behavioral adjustments such as hiding the ATM screen and looking at the person standing behind.

(3) Females, compared to males, give more importance to the sex of the person standing behind and perceive the space as being narrower than males.

(4) The preference of an ATM space designed for a single person depends on density conditions and the sex of the user. It is preferred in high density more than low density conditions and by females more than males.

\section{Results}

The demographic features of the respondents were derived from the questionnaire. The group consisted of 49.5 per cent female and 50.5 per cent male. Of the group 50 per cent were graduates of high school, 37.5 per cent university and the remaining were either primary (1\%) or secondary school (11.5\%) graduates; 82.5 per cent of the respondents had an occupation, whereas the others $(17.5 \%)$ did not. The overall mean age was 43 years. This information is used only for exhibiting the heterogeneity of the respondent group. Table 1 presents the number of same sex and different sex pairings under both density conditions. A further quota was applied to obtain these situations. In order to test the hypotheses, the chi-square test was applied.

For the first hypothesis, the relation between density conditions and distance preferences was examined. They were not independent $\left(\chi^{2}=62 \cdot 49\right.$, df. $=2$, $p<0.0001)$. Thus, hypothesis 1 was not rejected by the analysis. Of the subjects $80 \cdot 2$ per cent maintained a distance interval of $15-45 \mathrm{~cm}$ when in a high density situation, whereas the remaining subjects (19.8\%) maintained this distance interval in low density situations. For the second part of this hypothesis, the perception of space size was investigated under different density conditions. This relationship was verified by the analysis $\left(\chi^{2}=30.55\right.$, df. $\left.=2, p<0 \cdot 0001\right)$. So, the
TABLE 1

Sex pairings observed under both density conditions

\begin{tabular}{lcc}
\hline & High density & Low density \\
\hline Male-male & 26 & 24 \\
Male-female & 25 & 26 \\
Female-female & 25 & 23 \\
Female-male & 24 & 27 \\
Total & 100 & 100 \\
\hline
\end{tabular}

perception of space size was not independent of density conditions.

For the second hypothesis, the relation between density conditions and interpersonal distances between subjects was not independent in cases of the occurrence of behavior types such as looking at the person standing behind and hiding the ATM screen from others $\left(\chi^{2}=36.29\right.$, df. $=2, p<0.0001 ; \chi^{2}=41.85$, df. $=2, p<0.0001$, respectively). For the occurrence of looking at the person standing behind, most of the subjects observed under high density conditions had a smaller interpersonal distance between others $(73.8 \%)$; whereas in low density conditions this ratio is only $20 \%$. Second, for the occurrence of hiding the ATM screen, most of the subjects observed under high density conditions had a smaller interpersonal distance $(15-45 \mathrm{~cm})$ between others $(62 \%)$; whereas under low density conditions, only $15 \cdot 2 \%$ of the subjects maintained the same distance interval.

Also, the degree of annoyance with the presence of others standing behind and density conditions was not independent $\left(\chi^{2}=11.75\right.$, df. $\left.=2, p=0.0028\right)$. In high density situations 64 per cent of the individuals got very annoyed with the presence of others standing behind the ATM; whereas 44 per cent of the individuals in low density situations got very annoyed with the presence of others.

For the third hypothesis, the importance that an individual gives to the sex of the person standing behind was investigated. It was not independent of sex $\left(\chi^{2}=6.83\right.$, df. $\left.=2, p=0.0328\right)$. Among people who claimed the importance of the sex of the person standing behind, 63.2 per cent were females. However, the size perception was independent of sex. Size perception seemed to be affected by density conditions similarly for both sexes as indicated by the first hypothesis. All users perceived the space as being narrower in high density situations. The relationship between same sex and different sex pairings to interpersonal distance preferences under both density conditions was also investigated. It was found that same sex pairings under both density conditions had a smaller interpersonal distance interval between them than different sex pairings. For different 
sex pairings, a female's approach to a male was more distant than a male's approach to a female under both density conditions (see Table 2).

The relationship between density conditions and preference for a space designed for a single person was not verified. Of the subjects in high density and low density conditions 74 and 65 per cent, respectively, preferred an ATM space designed for a single person. People seem to prefer a more private space regardless of density conditions. Although the size perception was influenced by density conditions (hypothesis 1), it did not appear as a dominating factor on the need for a more private space.

Moreover, the respondent's preference for an ATM space designed for a single person was tested against sex and this preference appeared independent of sex. Despite the greater importance of sex difference for female respondents, both sexes wanted an ATM space designed for a single person $(72.3 \%$ of males and $66 \cdot 7 \%$ of females).

\section{Discussion}

People manipulate the physical environment and prefer to use various distances for social interaction depending on the people around and the activity taking place. Personal space is an important aspect of physical space as a part of the human-environment interface (Sommer, 1969). It serves to describe and communicate the requirements for individual privacy and the need for freedom of the person from unwanted intrusion by others (Gifford, 1987). In case of the activity analysed in this study, withdrawing money from an ATM, people would like to attain certain levels of privacy. It can be stated that people feel uncomforta- ble if they are approached at a distance that they judge as too close. The results of this research supported that under high density conditions people are more disturbed by the presence of others than in low density situations. First of all, this is because of the invasion of their personal space such that they are not able to attain desired levels of privacy in order to complete their activities. Second, when social density increases, interpersonal distance between subjects decreases and the feeling of being crowded increases. However, in this study, the preference of an ATM space designed for a single person indicates that the achieved privacy is not sufficient for this activity under both density conditions.

According to the literature, intrusion into personal space usually leads to withdrawal behaviors (Sommer, 1969). The findings of this research have clearly supported that the individuals in high density conditions often respond by increasing withdrawal behaviors. For this case, these behaviors include hiding the ATM screen from others and looking at the person standing behind. These kinds of responses are a function of the proximity of the intruder because the subjects under high density conditions have smaller interpersonal distance between other people. Some individuals even made verbal responses to the next person in the queue at ATM hall.

As well as this, people perceive the space as being narrower under high density conditions compared to low density. This is because of the increase in the number of people creating the social density. Although the results of the research have indicated that females give more importance to the sex of the person standing behind, this difference did not lead to any significant difference in their size perception. Additionally, both male and female subjects prefer an ATM space

TABLE 2

Distance preferences of same sex and different sex pairings under both density conditions

\begin{tabular}{|c|c|c|c|c|c|c|}
\hline & \multicolumn{2}{|c|}{$15-45 \mathrm{~cm}$} & \multicolumn{2}{|c|}{$46-75 \mathrm{~cm}$} & \multicolumn{2}{|c|}{$76-120 \mathrm{~cm}$} \\
\hline & Frequency & $\%$ & Frequency & $\%$ & Frequency & $\%$ \\
\hline \multicolumn{7}{|l|}{ High density } \\
\hline Male-male & 22 & 85 & 4 & 15 & & \\
\hline Male-female & 6 & 24 & 19 & 76 & & \\
\hline Female-female & 24 & 96 & 1 & 4 & & \\
\hline Female-male & 13 & 54 & 11 & 46 & & \\
\hline \multicolumn{7}{|l|}{ Low density } \\
\hline Male-male & 5 & 21 & 15 & 62 & 4 & 17 \\
\hline Male-female & 3 & 12 & 11 & 42 & 12 & 46 \\
\hline Female-female & 5 & 22 & 15 & 65 & 3 & 13 \\
\hline Female-male & 3 & 11 & 15 & 56 & 9 & 33 \\
\hline Total & 81 & & 91 & & 28 & \\
\hline
\end{tabular}


designed for a single person to prevent personal space invasions and maintain their privacy needs.

As mentioned before, personal characteristics of the individuals have an important role on interpersonal distancing. Similar to Rüstemli's study (1986), it has been found that same sex pairings - male-male and female-female - have a smaller interpersonal distance than different sex pairings under both density conditions. For same sex pairings, males have larger distances than females, whereas for different sex pairings, a female's approach to a male is more distant than a male's approach to a female under both density conditions.

Similarly, the results of this study, which indicate that females find the sex of the person standing behind more important than males, support Rüstemli's (1992, p. 57) findings. However, this difference does not affect their spatial preference probably because of the particular characteristics of the activity.

In general, it has been observed through the case study that both female and male subjects utilize smaller interpersonal distances while waiting in the queue at the ATM hall under high density conditions due to the limited space. This may also be because of the nature of this activity. People would like to perform their operations in a short period of time. If the operation of the person who is in front of the machine takes a longer time than expected, the ones waiting in the queue respond by leaving the ATM hall or by using smaller interpersonal distances to invade the personal space of the individual and make him/her uncomfortable to force the user to finish the operation immediately. Another function of smaller interpersonal distances might be to prevent accompanying or leaving people intervening into the queue.

According to the responses of the subjects, the preference for an ATM space designed for a single person is mostly shared. Therefore, the space can be designed for a single person in order to maintain both functional properties and individual needs for privacy. However, when the space is designed for a single person, the nature of the activity should be taken into consideration. This activity requires the users to complete their operations in a short period of time. Some individuals may need help from the person standing behind, and this makes the activity difficult for the person in a booth. As well as that, some branches have more than one ATM. In that case, there may be space restrictions. Still, it is possible to combine both a single-person, booth-like space and the existing open queue. When the ATM space is not designed for a single person, some adjustments can be proposed for waiting in a queue to avoid personal space intrusion and privacy reduction. One alternative can be a mark on the floor such as a line or a different floor pattern to define the personal distance of the user. A second alternative could be the installation of a turnstile to separate the interpersonal distance between the user and the one just standing behind. In this case, a circulation path could be manipulated in such a way that when the person completes the operation, he/she can directly go outside the ATM space. Furthermore, the orientation of ATM can be arranged so that the ones waiting in the queue are not able to see the ATM screen and the operation of the user. Shields at either sides of ATM screen may be helpful for this purpose. Finally, the individual who needs privacy can be separated from the others by a partition placed behind to reduce the probability of personal space invasion and to help attain desired levels of privacy.

\section{Acknowledgement}

The authors would like to thank anonymous reviewers for their helpful comments on the earlier version of this manuscript.

\section{Note}

Correspondence and reprint requests should be addressed to: Naz Kaya, Faculty of Art, Design and Architecture, Department of Interior Architecture and Environmental Design, Bilkent University, 06533, Ankara, Turkey; e-mail; naz@bilkent.edu.tr

\section{References}

Aiello, J. R. (1987). Human spatial behavior. In I. Altman \& D. Stokols (Eds) Handbook of Environmental Psychology. Vol. 1, New York: Wiley-Interscience, pp. 389-504.

Altman, I. \& Chemers, M. (1989). Culture and Environment. Cambridge: Cambridge University Press.

Baum, A. \& Greenberg, C. I. (1975). Waiting for a crowd: the behavioral and perceptual effects of anticipated crowding. Journal of Personality and Social Psychology 32, 671-679.

Baum, A. \& Paulus, P. B. (1987). Crowding. In I. Altman \& D. Stokols (Eds) Handbook of Environmental Psychology. Vol. 1, New York: Wiley-Interscience Publication, pp. 533-570.

Baxter, J. C. (1970). Interpersonal spacing in natural settings. Sociometry 33, 444-456.

Bechtel, R. B. \& Zeisel, J. (1990). Observation: the world under a glass. In R. B. Bechtel, R. W. Marans, \& W. Michelson (Eds) Methods in Environmental and Behavioral Research. New York: Krieger, pp. 11-40. 
Becker, F. D. (1973). Study of spatial markers. Journal of Personality and Social Psychology 26, 439-445.

Desor, J. A. (1972). Towards a psychological theory of crowding. Journal of Personality and Social Psychology 21, 79-83.

Evans, G. W. \& Howard, R. E. (1973). Personal space. Psychological Bulletin 80, 334-344.

Fisher, J. D. \& Byrne, D. (1975). Too close for comfort: sex differences in response to invasions of personal space. Journal of Personality and Social Psychology 32, $15-21$.

Gifford, R. (1982). Projected interpersonal distance and orientation choices: personality, sex, and social situation. Social Psychology Quarterly 45, 145-152.

Gifford, R. (1987). Environmental Psychology: Principles and Practice. Boston: Allyn.

Hall, E. T. (1966). The Hidden Dimension. New York: Doubleday.

Hayduk, L. A. (1983). Personal space: where we now stand. Psychological Bulletin 94, 293-335.

Horn, J. L. (1994). Crowding. In R. Corsini (Ed.) Encyclopedia of Psychology. Vol. 1, 2nd edn, New York: John Wiley, pp. 365-366.

Hortaçsu, N., Duzen, E., Arat, S., Atahan, D. \& Uzer, B. (1990). Intrusions upon same-sex or different sex dyads in a Turkish university dinning hall. International Journal of Psychology 25, 33-37.

Jain, U. (1987). Effects of population density and resources on the feeling of crowding and personal space. Journal of Social Psychology 127, 331-338.

Krail, K. \& Leventhal, G. (1976). The sex variable in the intrusion of personal space. Sociometry 39, 170-173.

Kuethe, J. L. (1962). Social schemas. Journal of Abnormal and Social Psychology 64, 31-38.

Larner, S. (1993). Sex and personal space. New Library World 94, 26-27.
Loo, C. (1977). Beyond the effects of crowding: situational and individual differences. In D. Stokols (Ed.) Perspectives on Environment and Behavior. New York: Plenum Press, pp. 153-168.

Marriott, F. H. C. (1990). A Dictionary of Statistical Terms. 5th Edn, New York: John Wiley.

Patterson, M. L., Mullens, S. \& Romano, J. (1971). Compensatory reactions to spatial intrusion. Sociometry 34, $114-121$.

Rüstemli, A. (1986). Male and female personal space needs and escape reactions. International Journal of Psychology 21, 503-511.

Rüstemli, A. (1992). Crowding effects of density of interpersonal distance. Journal of Social Psychology 132, 51-58.

Remland, M. S., Jones, T. S. \& Brinkman, H. (1995). Interpersonal distance, body orientation, and touch: effects of culture, gender, and age. Journal of Social Psychology 135, 281-297.

Sears, O. D., Peplau, A. \& Freedman, J. (1988). Social Psychology. Englewood Cliffs, NJ: Prentice Hall.

Sommer, R. (1959). Studies in personal space. Sociometry 22, 247-260.

Sommer, R. (1969). Personal Space: The Behavioral Basis of Design. Englewood Cliffs, NJ: Prentice Hall.

Sundstrom, E. (1975). An experimental study of crowding: effects of room size, intrusion, self-disclosure, and selfreported stress. Journal of Personality and Social Psychology 32, 645-654.

Veitch, R. \& Arkkelin, D. (1995). Environmental Psychology: An Interdisciplinary Perspective. New York: Prentice Hall.

Vogt, W. P. (1993). Dictionary of Statistics and Methodology. Newbury Park, California: Sage Publications.

Wollman, N., Kelly, B. M. \& Bordens, K. S. (1994). Environmental and intrapersonal predictors of reactions to potential territorial intrusions in the workplace. Environment and Behavior 26, 179-194. 